\title{
Acromegaly Due to McCune-Albright Syndrome
}

\author{
Martin J Rutkowski, ${ }^{1}$ Derek G Southwell, ${ }^{1}$ Tyler M Cardinal ${ }^{2}$ and Lewis S Blevins ${ }^{1}$ \\ 1. California Center for Pituitary Disorders, Department of Neurological Surgery, University of California, San FrancisCo, CA, USA; \\ 2. Department of Neurosurgery, Keck School of Medicine of University of Southern California, LOS Angeles, CA, USA
}

DOl: https://doi.org/10.17925/USE.2020.16.1.47

$\mathrm{M}$ cCune-Albright syndrome (MAS) is characterized by polyostotic fibrous dysplasia, café-au-lait hyperpigmentation of the skin, and acromegaly. Ablative therapy in affected patients must target the entire pituitary gland, making medical management the preferred therapy. Targeted medical therapies, including somatostatin and growth hormone (GH) receptor blockade, have shown promise in achievement of biochemical remission. We present the case of a 15-year-old girl with MAS who was discovered to have pituitary enlargement on computed tomography scan. She presented with café-au-lait spots, fibrous dysplasia of the sphenoid bone, and elevated insulin-like growth factor 1 and GH levels that failed to suppress on oral glucose tolerance testing. Treatment with a somatostatin analog was shown to be a safe and effective long-term management strategy of acromegaly that provides advantages over surgical resection.

\section{Keywords}

McCune-Albright, acromegaly, fibrous dysplasia, pituitary, somatotroph

Disclosure: Martin J Rutkowski, Derek G Southwell, Tyler M Cardinal and Lewis S Blevins have no financial or non-financial relationships or activities to declare in relation to this article.

Review Process: Double-blind peer review. Compliance with Ethics: Informed consent was obtained from the patient involved in this case study.

Authorship: The named authors meet the International Committee of Medical Journal Editors (ICMJE) criteria

for authorship of this manuscript, take responsibility for the integrity of the work as a whole, and have given final approval for the version to be published.

Access: This article is freely accessible at touchENDOCRINOLOGY.com (c) Touch Medical Media 2020.

Received: December 10, 2019

Accepted: March 12, 2020

Published Online: June 5, 2020

Citation: US Endocrinology. 2020;16(1):47-50

Corresponding Author: Martin J Rutkowski,

Department of Neurological Surgery, University of California, San Francisco, 505 Parnassus Avenue, M-779,

San Francisco, CA 94143, USA.

E: Martin.Rutkowski@ucsf.edu

Support: No funding was received in

the publication of this article.
McCune-Albright syndrome (MAS) is a genetic disorder first described by McCune ${ }^{1}$ and Albright ${ }^{2}$ in the 1930s as a triad of polyostotic fibrous dysplasia, café-au-lait spots, and precocious puberty (Figure 1). Since then, other hyperfunctioning endocrinopathies have been described in MAS, including hyperthyroidism, Cushing's syndrome, hypophosphatemic osteomalacia, and acromegaly. ${ }^{3}$ Patients with MAS display mosaicism as the disease results from a postzygotic mutation in the GNAS gene. GNAS is located on chromosome 20q13, which encodes for the stimulatory G protein alpha subunit (Gs $\alpha$ ). The mutation causes constitutive activation of $G s \alpha$, leading to constitutive activation of adenylate cyclase and generation of cyclic adenosine monophosphate (CAMP). ${ }^{4}$ The distribution of affected cells plays a significant role in patient presentation, with about $20 \%$ of patients with MAS presenting with acromegaly. ${ }^{5}$

Treatment of growth hormone $(\mathrm{GH})$ secreting pituitary adenomas in patients with MAS remains a challenge due to severe fibrous dysplasia of the skull base preventing access to the sella and the dangers of malignant transformation as a result of radiotherapy. As a result, medical management of MAS-associated acromegaly has been recommended as safe and effective. ${ }^{6}$ Somatostatin analogs and dopamine receptor agonists have traditionally been used, but often lead to only partial symptom and disease control.,7 More recently, Akintoye et al. showed that pegvisomant, a direct GH receptor antagonist, is an effective alternative in patients with MAS who are unresponsive to somatostatin analogs. ${ }^{3}$ Below, we describe a case of a 15-year-old girl with MAS who was a poor surgical candidate and in whom somatostatin analogs were used to achieve normalized insulin-like growth factor 1 (IGF-1) levels.

\section{Case presentation}

A 15-year-old girl with MAS and a history of fibrous dysplasia of the left femur, requiring open reduction and internal fixation, underwent computed tomography (CT) scan of the face and skull to evaluate a known history of fibrous dysplasia of the sphenoid bone. The pituitary gland was enlarged and it appeared there was a mass emanating from the undersurface of the gland. There was a large right-sided lesion that involved the body of the sphenoid, extended into the sphenoid sinus, and involved the right cavernous sinus. This lesion was thought to represent fibrous dysplasia of the sphenoid bone. A follow-up magnetic resonance image (MRI) was obtained (Figure 2).

She was referred to an endocrinologist for further evaluation of her abnormal pituitary gland. There were no historical features of acromegaly and there were no obvious gross acromegalic features on examination, including frontal bossing, prognathism, macroglossia, skin tags, hyperhidrosis, or hirsutism. There were no symptoms or signs of other anterior pituitary hormone excesses or deficiencies. Her height was similar to that of her older sister and was considered appropriate in relation to her estimated mid-parental height. There were several café-au-lait spots across her back. 
Figure 1: Clinical image of classic appearing café-au-lait skin pigmentation

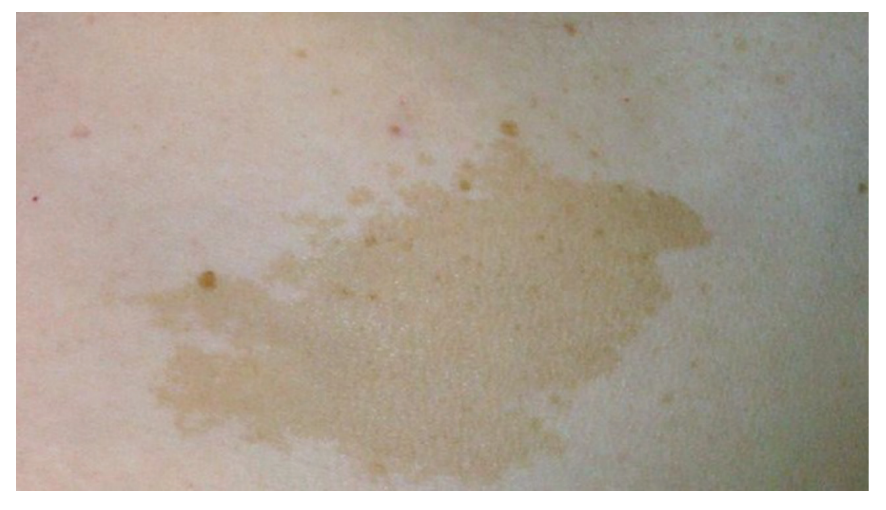

Table 1: Characteristics of 115 patients with McClune-Albright syndrome with acromegaly

\begin{tabular}{|c|c|}
\hline Presenting characteristics & $\mathrm{n}$ (\% of available data)* \\
\hline Male & $67(58)$ \\
\hline Female & $48(42)$ \\
\hline Precocious puberty & $44(41)$ \\
\hline Café-au-lait spots & $74(71)$ \\
\hline Craniofacial fibrous dysplasia & 112 (99) \\
\hline Polyostotic fibrous dysplasia & 107 (95) \\
\hline Macroadenoma & $43(70)$ \\
\hline Microadenoma & $18(30)$ \\
\hline \multicolumn{2}{|l|}{ Treatment and outcome } \\
\hline Somatostatin agonist & $47(41)$ \\
\hline Sensitive & $13(28)$ \\
\hline Partially sensitive & $23(49)$ \\
\hline Resistant & $11(23)$ \\
\hline Somatostatin + dopamine agonist & $20(17)$ \\
\hline Sensitive & $7(35)$ \\
\hline Partially sensitive & $9(45)$ \\
\hline Resistant & $4(20)$ \\
\hline Pegvisomant alone & $7(6)$ \\
\hline Sensitive & $6(86)$ \\
\hline Partially sensitive & $1(14)$ \\
\hline Resistant & 0 \\
\hline Somatostatin agonist + pevisomant & $7(6)$ \\
\hline Sensitive & $5(71)$ \\
\hline Partially sensitive & $2(29)$ \\
\hline Resistant & 0 \\
\hline Acromegaly controlled & $41(50)$ \\
\hline
\end{tabular}

*Not every case report contained a complete list of presenting characteristics, adenom classification, and treatment outcomes. Percentages were calculated based on the total number of available data points in order to more accurately represent the data.
Figure 2: Magnetic resonance imaging demonstrating sellar enlargement

A

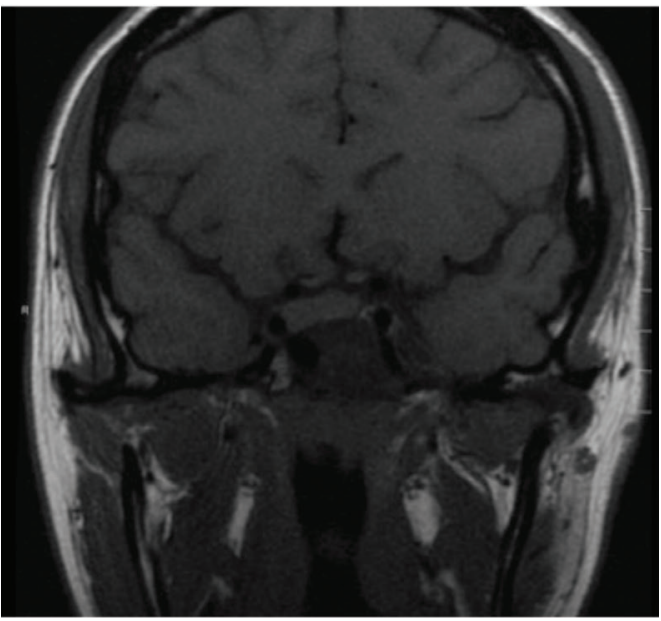

B

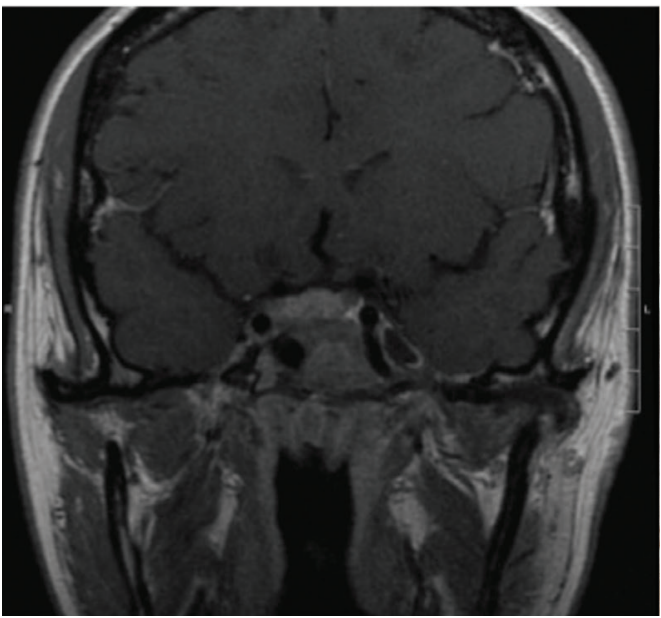

C

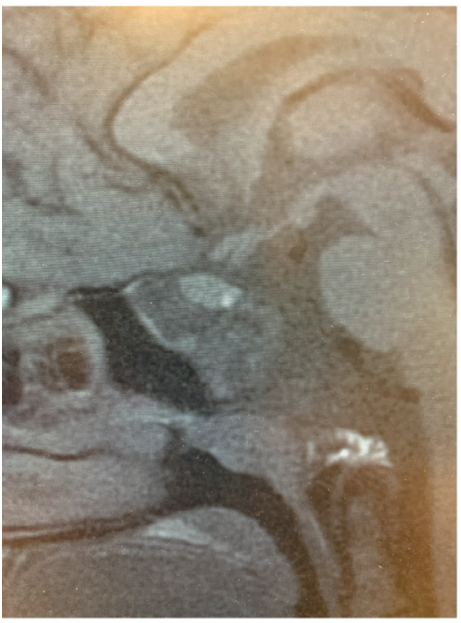

Pre- (A) and post-contrast (B) $T 1$ coronal, as well as sagittal (C). Note the apparent area of contrast enhancement extending into the right cavernous sinus representing an exophytic area of fibrous dysplasia similar in appearance to a pituitary adenoma. The mass was found to be contiguous with the sphenoid bone, rather than a discrete pituitary lesion. 
Figure 3: The GNAS mutation seen in McCune-Albright syndrome leads to constitutive activation of GS $\alpha$, leading to unregulated production of CAMP and transcription/translation of growth hormone

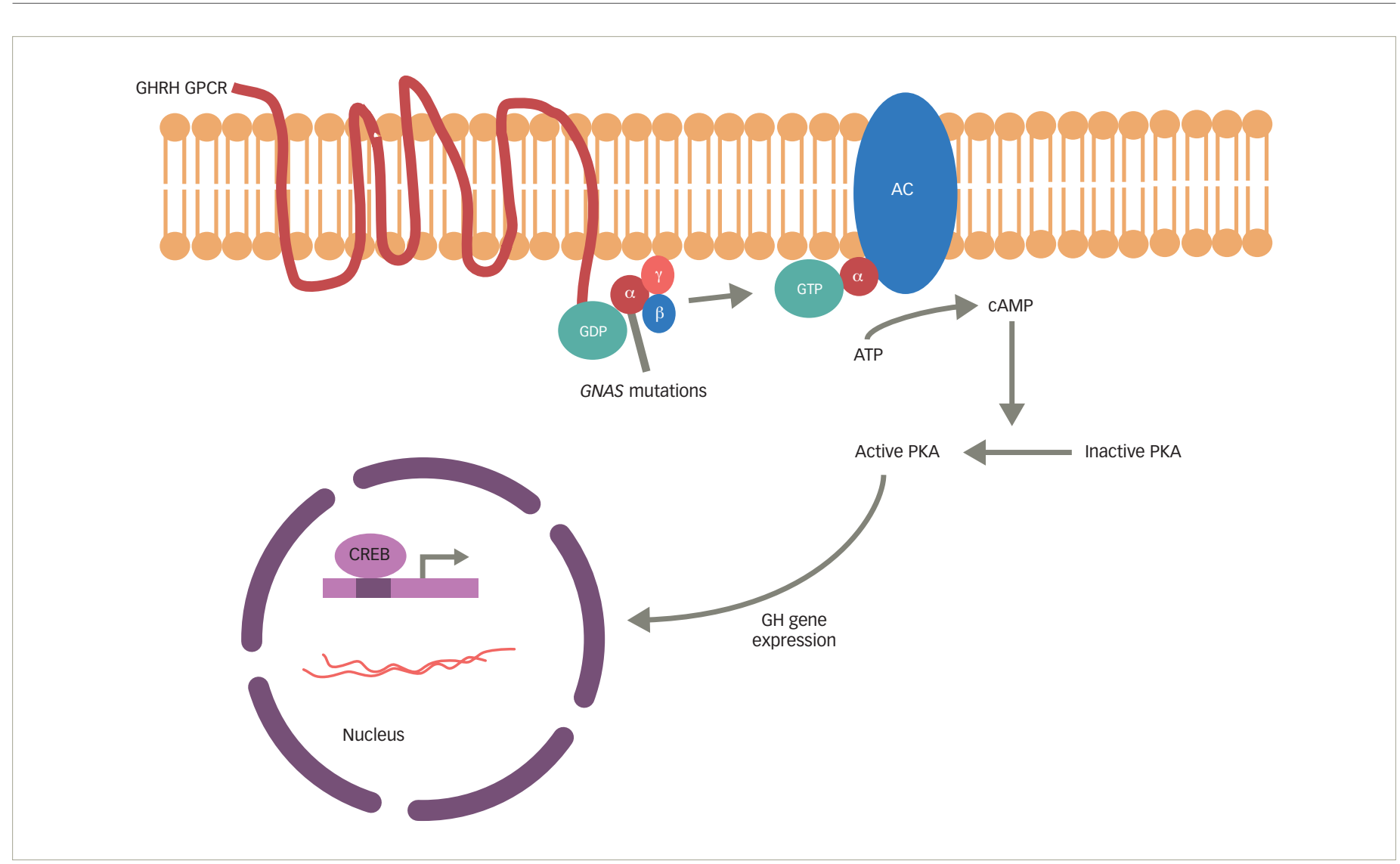

This mutation may explain the resistance to treatment with somatostatin analogues, which work by decreasing CAMP levels.

$A C=$ adenylyl cyclase; $A T P=$ adenosine triphosphate; $C A M P=$ cyclic adenosine monophosphate; $C R E B=C A M P$ response element-binding protein; GDP = guanosine diphosphate; $\mathrm{GH}=$ growth hormone; $\mathrm{GHRH}=$ growth hormone-releasing hormone; GPCR = G protein-coupled receptor; GTP= guanosine triphosphate; $P K A=$ protein kinase $A$.

Laboratory investigations revealed a GH level that was elevated measuring $26.5 \mathrm{mcg} / \mathrm{L}$. GH failed to suppress in response to oral glucose. The IGF-1 level was elevated at $791 \mathrm{ng} / \mathrm{mL}$. The serum prolactin concentration was normal. Other pituitary functions were normal.

She was treated with Sandostatin ${ }^{\circledast}$ (octreotide, Novartis, Basel, Switzerland) long-acting release (LAR) $20 \mathrm{mg}$ monthly. There were no side effects of treatment. There was no change in her overall sense of wellbeing. Her GH and IGF-1 levels fell to $16 \mathrm{mcg} / \mathrm{L}$ and $589 \mathrm{ng} / \mathrm{mL}$ respectively (age-adjusted normal range for IGF-1 was 217-589 ng/mL). The dose of Sandostatin LAR was increased to $30 \mathrm{mg}$ monthly in attempt to maximize biochemical control of GH hypersecretion. Her GH and IGF-1 levels fell to $10 \mathrm{mcg} / \mathrm{L}$ and $585 \mathrm{ng} / \mathrm{mL}$, respectively. Treatment was continued without side effects. Over the ensuing years, she experienced normal growth and achieved her estimated mid-parental stature.

\section{Discussion}

MAS is characterized by polyostotic fibrous dysplasia, café-au-lait hyperpigmentation of the skin, and hyperfunctioning endocrinopathies. ${ }^{8}$ The disorder is caused by sporadic mutations in GNAS, a gene that when mutated leads to mosaicism, wherein a mixed population of normal and abnormal cells are present to varying degrees in affected individuals. The clinical presentation is largely related to the extent and distribution of cells that possess the mutation. 5,9 Hyperthyroidism, Cushing's syndrome, and acromegaly are common hyperfunctioning endocrinopathies seen in MAS. ${ }^{6}$ In one large series of 112 treated patients, the mean age at presentation was $24 .{ }^{6}$ In general, gonadotropin-independent sexual precocity is the most common presentation, and affected patients commonly present with either symptoms of precocious puberty or those related to fibrous dysplasia as in our patient. 6,10

MAS-associated acromegaly has been reported previously in the literature, with varying degrees of treatment success (Table 1). In a study of 58 patients with MAS, 22 (38\%) had clinical and biochemical stigmata of acromegaly. ${ }^{5}$ Twelve patients (21\%) failed to suppress $\mathrm{GH}$ on an oral glucose tolerance test. Pituitary adenoma was identified on MRI of the sella in four of these 12 patients. Another study found clinical features of acromegaly in $20 \%$ of patients with MAS, with pituitary adenoma identified on MRI in $67 \%$ of those cases. ${ }^{11}$ This indicates a higher incidence of somatotroph adenomas in patients with MAS versus patients without MAS; the general incidence of $\mathrm{GH}$-secreting adenomas in patients without MAS is approximately $10-15 \% .{ }^{12}$ In addition, patients with MAS-associated acromegaly, present 10-20 years earlier than patients with classically described disease. ${ }^{6,13}$ Furthermore, the skeletal deformities that occur as a result of the fibrous dysplasia in MAS may mask the craniofacial changes often observed in acromegaly. ${ }^{6}$ Therefore, clinical testing for acromegaly, especially in a younger patient like the one presented in the current study, may be appropriate in all patients with MAS. 
In the patient presented here, acromegaly was diagnosed as a result of the workup of an abnormal pituitary gland visualized on MRI Serum prolactin levels were ultimately found to be within normal limits for our patient, though it is important to note that patients with MAS with GH hypersecretion can show elevated levels of prolactin, estimated as greater than $80 \%$ of patients. ${ }^{6}$ While the fibrous dysplastic lesions associated with MAS are best tracked by CT, MRI of the sella may be of clinical use in all patients with suspected MAS to identify pituitary abnormalities. ${ }^{14}$

Generally speaking, examination of resected pituitary tissue in patients with MAS who undergo surgery has illustrated widespread neoplasia within the gland. These findings suggest that resection of adenomas associated with MAS may not result in long-term GH control in these patients. Ablative therapy in affected patients must target the entire pituitary gland to increase the likelihood of successful control of the GH hypersecretion and the clinical manifestations of acromegaly. ${ }^{15}$ Furthermore, fibrous dysplasia of the sphenoid bone, as seen in our patient and others, may preclude successful transsphenoidal approach to the sella. For these reasons, most patients with MAS are not candidates for pituitary surgery.

In this patient, surgery was not considered a rational therapeutic option due to dysplastic changes precluding safe anatomical approach and resection, and because it appeared that the patient had a generalized disorder of her pituitary gland, rather than a discrete adenoma. For her, and many other patients with MAS-associated acromegaly, medical management of $\mathrm{GH}$ and IGF-1 excess is of paramount importance. Somatostatin analogs are effective in normalizing IGF-1 levels in about $50 \%$ of patients. ${ }^{7}$ However, in patients with MAS with acromegaly whose disease is not controlled by somatostatin analogs, pegvisomant, a $\mathrm{GH}$ receptor antagonist, may be useful as it has been shown to reduce IGF-1 levels in this population. 3,4,10 Resistance to somatostatin analogs may be due to the $\mathrm{G}$ protein-coupled receptor-mediated pathogenesis of MAS, which may be better treated via direct receptor antagonism (Figure 3). Nevertheless, long-acting somatostatin analogs are still indicated as first-line therapy for acromegaly in patients with MAD due to the convenience of only requiring one injection per month. In this patient, Sandostatin LAR $30 \mathrm{mg}$ monthly was sufficient to adequately control disease.

The efficacy of radiotherapy in these patients is uncertain and there remain concerns regarding the possibility of sarcomatous transformation of fibrous dysplasia. ${ }^{6.12}$ Thus, it is not our policy to offer radiotherapy to children or young adults with MAS unless surgery is contraindicated and there has been no demonstrable biochemical response to pharmacologic agents.

In summary, we offer further evidence that acromegaly associated with MAS may present earlier and with different clinical signs and symptoms than classic stigmata of acromegaly, such as frontal bossing, hyperhidrosis, or hirsutism; and instead exhibit unique features such as craniofacial deformity and endocrinopathy including hyperprolactinemia. MRI of the sella may be indicated in all patients with MAS to assess for the existence of a pituitary adenoma. Medical management is often preferable over surgery in this patient population due to fibrous dysplasia of the bones preventing safe and reliable access to the sella. If patients are refractory to treatment with somatostatin analogs, the $\mathrm{GH}$ receptor antagonist pegvisomant may be effective in achieving disease control. $\square$
1. McCune DJ. Osteitis fibrosa cystica: the case of a nine year old girl who also exhibits precocious puberty, multiple pigmentation of the skin and hyperthyroidism. Am J Dis Child. 1936;52:743-7.

2. Albright F, Butler AM, Hampton AO, Smith P. Syndrome characterized by osteitis fibrosa disseminata, areas of pigmentation and endocrine dysfunction, with precocious puberty in females: report of five cases. N Eng/ J Med. 1937;216:727-46

3. Akintoye SO, Kelly MH, Brillante B, et al. Pegvisomant for the treatment of gsp-mediated growth hormone excess in patients with McCune-Albright syndrome. J Clin Endocrinol Metab. 2006;91:2960-6.

4. Horvath A, Stratakis CA. Clinical and molecular genetics of acromegaly: MEN1, Carney complex, McCune-Albright syndrome familial acromegaly and genetic defects in sporadic tumors. Rev Endocr Metab Disord. 2008;9:1-11.

5. Akintoye SO, Chebli C, Booher S, et al. Characterization of gsp-mediated growth hormone excess in the context of McCune-Albright syndrome. I Clin Endocrinol Metab. 2002;87:5104-12.
6. Salenave S, Boyce AM, Collins MT, Chanson P. Acromegaly and Mccune-Albright syndrome J Clin Endocrinol Metab. 2014:99:1955-69

7. Galland F, Kamenicky P, Affres H, et al. McCune-Albright syndrome and acromegaly: effects of hypothalamopituitary radiotherapy and/or pegvisomant in somatostatin analog-resistant patients. J Clin Endocrinol Metab. 2006;91:4957-61.

8. VölkI TM, Dörr HG. McCune-Albright syndrome: clinical picture and natural history in children and adolescents. J Pediatr Endocrinol Metab. 2006:19:551-9.

9. Weinstein LS. G(S)alpha mutations in fibrous dysplasia and McCune-Albright syndrome. J Bone Miner Res. 2006; 21(Suppl. 2):P120-4.

10. Holbrook L, Brady R. McCune Albright Syndrome. In: StatPearls [internet]. Treasure Island (FL): StatPearls Publishing, 2019. Available at: www.ncbi.nlm.nih.gov/books/NBK537092/ (accessed March 20, 2020)

11. Boyce AM, Glover M, Kelly MH, et al. Optic neuropathy in McCune-Albright syndrome: effects of early diagnosis and treatment of growth hormone excess. I Clin Endocrinol Metab. 2013:98:E126-34.

12. Larkin S, Ansorge O. Pathology and pathogenesis of pituitary adenomas and other sellar lesions. In: Feingold KR, Anawalt B, Boyce A, et al. Endotext [internet]. South Dartmouth (MA): MDText.com Inc.; 2017. Available at: www.ncbi.nlm.nih.gov/ books/NBK425704/ (accessed March 20, 2020).

13. Yao $Y$, Liu $Y$, Wang $L$, et al. Clinical characteristics and management of growth hormone excess in patients with McCune-Albright syndrome. Eur J Endocrinol. 2017;176:295-303.

14. O'Laughlin RL, Selinger SE, Moriarty PE. Pituitary adenoma in McCune-Albright syndrome: MR demonstration. J Comput Assist Tomogr. 1989;13:685-8.

15. Vortmeyer AO, Gläsker S, Mehta GU, et al. Somatic GNAS mutation causes widespread and diffuse pituitary disease in acromegalic patients with McCune-Albright syndrome. J Clin Endocrinol Metab. 2012;97:2404-13. 